\title{
A comparative assessment of caries risk using cariogram among smokers and smokeless tobacco users in india - a cross-sectional study
}

\author{
Nandini Sen, Kailash Asawa, Nagesh Bhat, Mridula Tak, Pratibha Sultane, Tulip Chakravarty
}

Dept. of Public Health Dentistry, Pacific Dental College and Hospital, Debari, Udaipur, Rajasthan, India.

\section{Emails:}

Nandini Sen, Phone: +91-9521664698.E mail: sen_ty31@yahoo.co.in; Kailash Asawa, Email: kailashasawaudr@yahoo.com; Nagesh Bhat, Email: communitydentist@gmail.com; Mridula Tak, Email: mtak1084@gmail.com; Pratibha Sultane, Email: 090pratibha@gmail.com; Tulip Chakravarty, Email: dr.tulip09@gmail.com

\begin{abstract}
Background: A dearth of literature exists concerning utilization of the unique cariogram model for caries risk assessment in tobacco users.

Objective: To assess \& compare caries risk among smokers \& smokeless tobacco users using Cariogram model.

Methods: A descriptive cross sectional study was conducted among smokers and smokeless tobacco users of Udaipur for 3 months. Caries risk assessment was done by employing a survey proforma based on the Cariogram model. Statistical analysis included descriptive statistics, Chi-square test followed by Marascuilo procedure and Stepwise multiple linear regression with 95\% confidence interval and 5\% significance level.
\end{abstract}

Results: Majority of the smokers (56\%) portrayed high caries risk (less chance to avoid new caries) followed by smokeless Tobacco users (34\%). Only 40\% smokeless tobacco users had relatively high chances $(>60 \%)$ of avoiding future new caries. The susceptibility sector of the cariogram model contributed primarily to caries risk in the study population.

Conclusion: The study findings from the different cariogram elements converged to indicate that smokers were at maximum caries risk, followed by smokeless tobacco users and therefore Cariogram model could be a useful tool to represent caries risk among smokers and smokeless tobacco users.

Keywords: Smokers, cariogram, smokeless tobacco, dental caries, sugar.

DOI: https://dx.doi.org/10.4314/ahs.v18i4.26

Cite as: Sen N, Asawa K, Bhat N, Tak M, Sultane P, Chakravarty T. A comparative assessment of caries risk using cariogram among smokers and smokeless tobacco users in india - a cross-sectional study. Afri Health Sci. 2018;18(4): 1046-1056. https://dx.doi.org/10.4314/abs. $v 18 i 4.26$

\section{Introduction}

Globally tobacco usage enforces an enormous impact on public health and its burden is on the rise progressively.

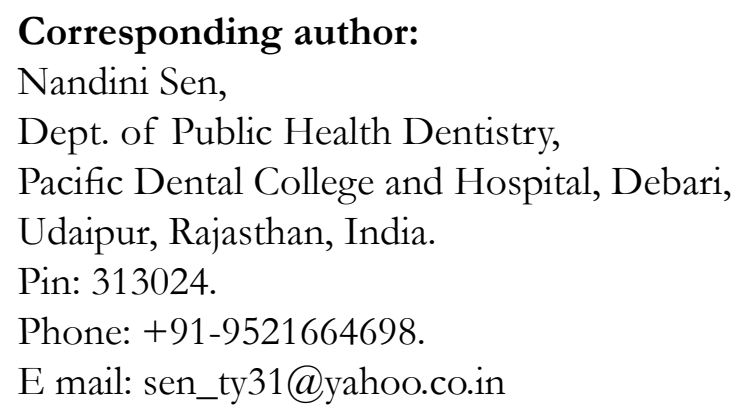

The World Health Organization predicts that deaths due to tobacco consumption may exceed 1.5 million yearly by $2020^{1}$. The huge tobacco consumption in the Indian subcontinent lead to almost $10 \%$ of total mortality (1 million) in 2010 and its usage soared up from 79 million to 108 million in the 15-69 years age group by $2015^{2,3}$.

Tobacco usage has definite correlations with occurrence of dental caries worldwide ${ }^{4-7}$. Both the smoking and non-smoking forms of tobacco use have their respective negative impacts on oral health producing caries susceptible conditions such as reduced salivary flow, acidic $\mathrm{pH}$, increased microbial count. Shalini et al confirmed this

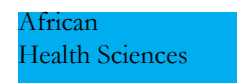

(C) 2018 Sen et al. Licensee African Health Sciences. This is an Open Access article distributed under the terms of the Creative commons Attribution License (https://creativecommons.org/licenses/BY/4.0), which permits unrestricted use, distribution, and reproduction in any medium, provided the original work is properly cited. 
fact on truck drivers in North Chennai, India that mean DMFT score was higher for smokers than for smokeless tobacco users ${ }^{8}$. A study by Singh et al on male adults in Uttar Pradesh, India showed that long term smoking significantly reduced the salivary flow rate and $\mathrm{pH}^{9}$.

Association of smokeless tobacco use and increased dental caries can be attested to the fact that in the pouch and plug varieties of smokeless tobacco forms, sugar is usually found to be present ${ }^{10,11}$. Winn DM in his review article illustrated that caries incidence is higher in smokeless tobacco users ${ }^{11}$.

In recent literature, Caries risk assessment has acquired immense attention as a principal component in comprehensive management of the disease. In 1997, Dr. Bratthall introduced an interactive computer programme named as Cariogram, which is the sole model capable of evaluating diverse factors like microflora, host response, oral health status and cariogenic diet involved in caries augmentation $^{12}$. Thus, it is useful in assessing caries risk as also shown in the studies by Raju et al and Celik et $\mathrm{al}^{13,14}$.

Nagarajappa et al conducted a cross-sectional study among smokeless tobacco chewers and non-chewers where the authors had assessed caries risk using DMFS scores and concluded that a higher percentage of caries was associated with numbers of Lactobacillus species in the population ${ }^{15}$. Again, Mujahid et al conducted a descriptive study to examine the relationship of caries risk, salivary $\mathrm{pH}$, and levels of cariogenic Streptococcus and Lactobacillus in relation to tobacco abuse. The authors concluded that long term use of tobacco could cause significant alterations in salivary $\mathrm{pH}$, bacterial count which could render oral mucosa vulnerable to dental caries ${ }^{16}$. Studies by Barman \& Umesh, Lashkari \& Shukla, Shalini et al utilized DMFT index scores, assessed salivary flow rate and $\mathrm{pH}$ for dental caries prevalence ${ }^{8,17,18}$.

Thus it can be clearly stated that there is a lack in literature associating caries prevalence $\&$ its risk with the various risk factors in a comprehensive way. Neither of the studies were found to correlate all the suspected causal factors with dental caries among tobacco users nor used any specialized tool other than Cariogram.

But till now, no studies have been conducted to assess and compare the caries risk among smokers and smokeless tobacco users using Cariogram model. Hence, based on the scarce information available on the performance of Cariogram in adults and to fill the existing void in literature regarding the utility of Cariogram in determining caries risk in smokers and smokeless tobacco users, the present study was conducted with the aim to assess \& compare caries risk using Cariogram among smokers \& smokeless tobacco users in Udaipur city, Rajasthan, India.

\section{Methods}

Study design, area, duration and population

A descriptive cross sectional study was conducted among smokers and smokeless tobacco users along with a control group visiting the out-patient department of a dental college and hospital, Udaipur city, Rajasthan in the month of May - July 2017.

\section{Ethical approval, official permission \& informed consent}

The study protocol was reviewed and approved by the Institutional Review Board and the ethical committee of dental college and hospital and was granted ethical clearance. An informed consent was obtained for all the individuals who participated in the study before the start of the examination.

\section{Training and calibration}

Before the commencement of the study, the examiner was standardized and calibrated. The intra examiner reliability for Decayed Missing Filled Teeth (DMFT) index (1938) and Modified Plaque Index - Loe H. (1967) was assessed using Kappa statistics which was found to be $86 \%$ and $80 \%$ respectively.

\section{Inclusion criteria}

Age range of study subjects was within $18-50$ years old, smokers were those subjects who smoked more than 5 cigarettes or bidis daily for more than 1 year. Smokeless tobacco users were those who had habit of chewing any form of tobacco more than 3 times a day for more than 1 year.

Exclusion criteria: Subjects with prosthesis, fixed orthodontic appliances, under medication which can alter salivary parameters, antibiotic therapy, history of radiothera- 
py, combination usage of tobacco, alcohol consumption, systemic disease, used mouthwash or undergone oral prophylaxis in past 1 month, uncooperative patients.

\section{Proforma details}

A survey proforma was designed which consisted of two sections, Section I consisted of general demographic information including name, age, sex, adverse habits and Section II comprised of information about the 9 Cariogram parameters - caries experience, related general disease, diet content, diet frequency, plaque amount, mutans streptococci count, fluoride programme, saliva secretion amount, saliva buffer capacity.

\section{Pilot survey}

A pilot study was conducted on 10 subjects from each group, smokers and smokeless tobacco users to determine the feasibility of the study, the time required for examination of each subject, to get acquainted to the laboratory procedure for salivary analysis and for sample size calculation. According to the data obtained for the Cariogram parameters, the mean and standard deviation of "Actual chance to avoid new caries" (Green sector) was calculated from the Cariogram software for both the study groups,

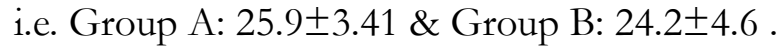

\section{Sample size determination}

Based on the results obtained from the pilot study, sample size (n) was determined with $95 \%$ confidence interval, $5 \%$ allowable error and $80 \%$ power of the study using the following formula:
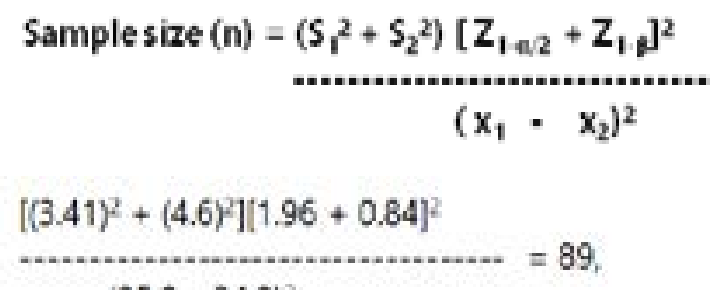

$(25.9-24.2)^{2}$

which was rounded off to 100 .

S1 = Standard deviation of Group A: Smokers (3.41), S2 = Standard deviation of Group B: Smokeless tobacco users (4.6), $\mathrm{x} 1=$ Mean percentage of actual chance to avoid new caries in Group A: Smokers group (25.9), x2 = Mean percentage of actual chance to avoid new caries in Group B: Smokeless tobacco users group (24.2), Z1- $\alpha / 2$
$=$ Value of the Normal Deviate at considered level of significance (1.96 for 5\% level of Significance), Z1- $\beta=$ Value of the Normal Deviate at considered power of the study ( 0.84 for $80 \%$ power of the study).

Final sample size was estimated to be 100 for both the groups, i.e. 50 patients to be selected for each of Group A: Smokers and Group B: Smokeless tobacco users. 50 patients were selected for control group who were normal healthy individuals without any history of the habit.

\section{Methodology}

Study participants were selected by simple random sampling method based on inclusion and exclusion criteria. Investigator screened all patients visiting the OPD of the dental college $\&$ hospital during 3-4 hours each day 4 times a week, although number of subject selection varied from $1-5$ per day. Patients who met the inclusion and exclusion criteria of both groups, i.e. smokers and smokeless tobacco users were particularly scrutinized and selected. Firstly, they were interviewed regarding socio-demographic data, diet frequency and fluoride exposure. Clinical examination was done to measure caries experience and plaque amount using DMFT (1938) and modified Plaque Index (Loe H.-1967) respectively.

According to the Modified Plaque Index - Loe H. $(1967)^{19}$, the scoring criteria for assessment of plaque were as follows: 0 - No plaque, 1 - A film of plaque adhering to the free gingival margin and adjacent area of the tooth. The plaque may be recognized by running a probe across the tooth surface, 2 - Moderate accumulation of soft deposits within the gingival pocket, on the gingival margin and/or adjacent tooth surface, which can be seen by the naked eye, 3 - Abundance of soft matter within the gingival pocket and/or on the tooth and gingival margin. The plaque score was calculated for each subject and categorized as Low - 0.1-0.9, Moderate - 1.0-1 .9 and High 2.0-3.0 plaque amount scores.

Instruments used during examination, saliva flow rate and $\mathrm{pH}$ measurement were: plain mouth mirrors, explorers, tweezers, kidney trays, disposable mouth masks and gloves, cotton swabs, paraffin wax, plastic graduated test tubes, plastic funnels, measuring cups, Indikrom $\mathrm{pH}$ indicating papers. 
Salivary parameters estimation: Salivary flow rate estimation was done by collecting stimulated saliva sample within the morning hours (between 10.00 AM - 11.30 AM) to maintain circadian rhythm. The study participants were asked to spit in a funnel connected to a graduated test tube after every 1 minute for 5 minutes and expressed in $\mathrm{ml} / \mathrm{min}$. Colorimetric method using Indikrom papers was used to estimate the buffer capacity of saliva.

Microbiological analysis: Using an inoculation loop, sample was streaked on Mitis salivarius bacitracin agar (MSB) medium, which is selective for mutans streptococci and on Rogosa SL agar medium for lactobacilli. The colony counts were made using electron microscope and expressed in number of CFU (Colony Forming Units) per $\mathrm{ml}$ of saliva.

Assessment of caries risk profile: Cariogram is a graphical model which presents the caries risk profile of an individual, simultaneously taking into account the interaction of different causative factors of caries. It is divided into 5 sectors, in the following colours: green, dark blue, red, light blue and yellow indicating the different groups of factors related to dental caries.

The green sector shows an estimation of the "Actual chance to avoid new cavities". The green sector is "what is left, when the other factors have taken their share'. The dark blue sector 'Diet' is based on combination of diet content (lactobacilli content) and diet frequency. The red sector 'Bacteria' is based on the combination of amount of plaque and mutans streptococci. The light blue sector 'Susceptibility' is based on the combination of fluoride program,saliva secretion and saliva buffer capacity. The yellow sector 'Circumstances' is based on a combination of past caries experience and related disease.

Scores from each of the 9 parameters when entered, the software produces a pie diagram which represents the percentages of 'Diet' (Dark Blue), 'Bacteria' (Red), 'Susceptibility' (Light Blue), 'Circumstances' (Yellow). These 4 sectors dictate the percentage of 'Chance to avoid new caries' (Green) sector. Hence the bigger the green sector, the lesser is the risk of caries and vice versa.
The bigger the green sector, it is considered better from dental health point of view. Small green sector means low chance of avoiding caries which indirectly means high caries risk.

\section{Assessment of caries risk profile}

Since India is a developing nation and vulnerable for dental caries, 'High risk' category was opted for Country. For every individual, the cariogram parameters were given a score and entered into the cariogram computer program to obtain the individual caries risk profile.

\section{Statistical analysis}

The recorded data and cariogram software data were compiled and entered in Microsoft Excel 2007 and then exported to data editor page of SPSS version 20.0 (SPSS Inc., Chicago, Illinois, USA). Descriptive statistics included computation of percentages. Chi-Square Test $\left(\chi^{2}\right)$ followed by Marascuilo procedure for inter-group comparison was done through XLStat software version 2017.4. Caries risk was the primary outcome measure obtained as a continuous quantitative variable determined by the leftover fraction deducting the percentage of actual chance to avoid new caries (Green sector), while caries experience, related general disease, diet content, diet frequency, plaque amount, mutans streptococci count, fluoride programme, saliva secretion amount, saliva buffer capacity, adverse habits were treated as the explanatory variables (Qualitative data). Stepwise multiple linear regression analysis was done to estimate the relationship between caries risk and the significant predictor variables of the cariogram to build up the best fitted model depicting caries risk in the study population from amongst the 9 parameters of the cariogram model. For all tests, confidence interval and p-value were set at $95 \%$ and $\leq 0.05$ respectively.

\section{Results}

Overall, the study population was divided in 3 groups: smokers, smokeless tobacco users and control group. Demographic data showed that all the subjects of smokers group were males [ $\mathrm{n}=50(100 \%)]$, while smokeless tobacco users group comprised of 47 males $(94 \%)$ and 3 females $(6 \%)$ (Table 1). 
Table 1: Distribution of study population according to gender and tobacco usage habits

\begin{tabular}{|lcccc|}
\hline & $\begin{array}{c}\text { Smokers } \\
\mathbf{n}(\%)\end{array}$ & $\begin{array}{c}\text { Smokeless } \\
\text { Tobacco Users } \\
\text { n (\%) }\end{array}$ & $\begin{array}{c}\text { Control Group } \\
\text { n (\%) }\end{array}$ & $\begin{array}{c}\text { Total } \\
\text { n (\%) }\end{array}$ \\
$\begin{array}{l}\text { Male } \\
\text { Female }\end{array}$ & $50(100)$ & $47(94)$ & $45(90)$ & $142(94)$ \\
$\begin{array}{l}\text { Total } \\
\text { n (\%) }\end{array}$ & 0 & $3(6)$ & $5(10)$ & $8(6)$ \\
\hline
\end{tabular}

Majority of the smokers $[\mathrm{n}=20(40 \%)]$ depicted "Moderate" (DMFT 2) caries experience while maximum proportion of smokeless tobacco users [n=29 (58\%)] showed "low" (DMFT 1) caries experience. The DMFT scores were statistically significantly associated with the three study groups $(\mathrm{p}=0.001)$. Only $10 \%$ of the controls were found to have "moderate" (DMFT 2) caries experience scores.

"High" plaque amount scores were observed among smokers $[\mathrm{n}=35(70 \%)]$ while most of the smokeless tobacco users $[\mathrm{n}=41(82 \%)]$ portrayed "Moderate" plaque amount score. Plaque amount was found to have a statistically significant association with the three study groups (p-value $<0.001)$.

Maximum participants of smokers group showed "High"
Streptococcus mutans count in their saliva $[\mathrm{n}=22(42 \%)]$, whereas majority of smokeless tobacco users $[n=23$ (46\%)] were mainly found to be in the "Moderate" $S$. mutans count category. In intergroup comparison, a statistically significant difference was found between Smokers and smokeless tobacco users groups for "Low" and "High" S. mutans count categories. Study subjects of all the three groups illustrated regular usage of fluoridated toothpaste $(52 \%, 62 \%$ and $68 \%$ respectively).

Majority of the smokers ( $92 \%$ ) were found to have "low" saliva secretion, while smokeless tobacco users and controls primarily depicted normal saliva secretion $(66 \%$ and $94 \%$ respectively). Smokers $[\mathrm{n}=26(52 \%)]$ were mostly found to have "Reduced" salivary $\mathrm{pH}$ (4.5-5.5), while smokeless tobacco users had "Adequate" $(\geq 6.0)$ salivary $\mathrm{pH}(56 \%)$ (Table 2). 


\section{Table 2: The comparative assessment of study participants based on parameters used in Cariogram model}

\begin{tabular}{|c|c|c|c|c|}
\hline & $\begin{array}{c}\text { Smokers } \\
\text { n (\%) }\end{array}$ & $\begin{array}{c}\text { Smokeless } \\
\text { Tobacco } \\
\text { Users } \\
\text { n (\%) }\end{array}$ & $\begin{array}{c}\text { Control } \\
\text { Group } \\
\text { n (\%) }\end{array}$ & p-value \\
\hline \multicolumn{5}{|l|}{ Caries experience Score } \\
\hline Very low (DMFT 0) & $1(2.0)^{\mathrm{ab}}$ & $11(22.0)^{\mathrm{ac}}$ & $34(68.0)^{\mathrm{bc}}$ & \\
\hline Low (DMFT 1) & $13(26.0)^{\mathrm{d}}$ & $29(58.0)^{\mathrm{de}}$ & $11(22.0)^{\mathrm{e}}$ & \\
\hline Moderate (DMFT 2) & $20(40.0)^{\mathrm{fg}}$ & $8(16.0)^{\mathrm{f}}$ & $5(10.0)^{g}$ & $0.001^{*}$ \\
\hline High $(\mathrm{DMFT} \geq 3)$ & $16(32.0)^{\mathrm{hi}}$ & $2(4.0)^{\mathrm{h}}$ & $0^{\mathrm{i}}$ & \\
\hline \multicolumn{5}{|l|}{ Diet Content (Lactobacilli count) Score } \\
\hline Very low ( $\leq 10^{3} \mathrm{CFU} / \mathrm{ml}$, very low sugar consumption) & $22(44.0)^{\mathrm{a}}$ & $36(72.0)^{\mathrm{b}}$ & $44(88.0)^{\mathrm{ab}}$ & \\
\hline Low ( $10^{4} \mathrm{CFU} / \mathrm{ml}$, low sugar consumption $)$ & $26(52.0)^{\mathrm{cd}}$ & $13(26.0)^{\mathrm{c}}$ & $6(12.0)^{\mathrm{d}}$ & $0.001 *$ \\
\hline Moderate $\left(10^{5} \mathrm{CFU} / \mathrm{ml}\right.$, moderate sugar consumption $)$ & $2(4.0)^{\mathrm{e}}$ & $1(2.0)^{f}$ & $0^{\mathrm{g}}$ & \\
\hline High ( $\geq 10^{6} \mathrm{CFU} / \mathrm{ml}$, high sugar consumption) & 0 & 0 & 0 & \\
\hline \multicolumn{5}{|l|}{ Diet Frequency Score (meals/day) } \\
\hline 3 & $22(44.0)^{\mathrm{a}}$ & $36(72.0)^{\mathrm{b}}$ & $44(88.0)^{\mathrm{ab}}$ & \\
\hline Maximum 5 & $24(48.0)^{\mathrm{cd}}$ & $13(26.0)^{\mathrm{ce}}$ & $5(10.0)^{\mathrm{de}}$ & $0.001 *$ \\
\hline Maximum 7 & $4(8.0)^{\mathrm{fg}}$ & $1(2.0)^{f}$ & $1(2.0)^{\mathrm{g}}$ & \\
\hline$>7$ & 0 & 0 & 0 & \\
\hline \multicolumn{5}{|l|}{ Plaque Amount Score } \\
\hline Very low (0-Excellent) & $0^{\mathrm{a}}$ & $1(2.0)^{\mathrm{b}}$ & $11(22.0)^{\mathrm{ab}}$ & \\
\hline Low $(0.1-0.9$ Good $)$ & $7(14.0)^{\mathrm{c}}$ & $6(12.0)^{\mathrm{d}}$ & $36(72.0)^{\mathrm{cd}}$ & $0.001 *$ \\
\hline Moderate (1.0-1.9 Fair) & $8(16.0)^{\mathrm{e}}$ & $41(82.0)^{\mathrm{ef}}$ & $3(6.0)^{f}$ & \\
\hline High (2.0-3.0 Poor) & $35(70.0)^{\mathrm{gh}}$ & $2(4.0)^{\mathrm{g}}$ & $0^{\mathrm{h}}$ & \\
\hline \multicolumn{5}{|l|}{ Mutans Streptococci Score } \\
\hline Very low $(\leq 20,000 \mathrm{CFU} / \mathrm{ml}$ Saliva $)$ & $3(6.0)^{\mathrm{a}}$ & $8(16.0)^{b}$ & $44(88.0)^{\mathrm{ab}}$ & \\
\hline Low $(20,000-1,00,000 \mathrm{CFU} / \mathrm{ml}$ Saliva $)$ & $4(8.0)^{\mathrm{c}}$ & $17(34.0)^{\mathrm{cd}}$ & $5(10.0)^{\mathrm{d}}$ & $0.001 *$ \\
\hline Moderate $(>1,00,000-1$ million CFU/ml Saliva) & $21(42.0)^{\mathrm{e}}$ & $23(46.0)^{\mathrm{f}}$ & $1(2.0)^{\mathrm{ef}}$ & \\
\hline High ( $>1$ million CFU/ml Saliva) & $22(44.0)^{\mathrm{gh}}$ & $2(4.0)^{\mathrm{g}}$ & $0^{\mathrm{h}}$ & \\
\hline \multicolumn{5}{|l|}{ Fluoride Programme } \\
\hline Maximum fluoride programs & 0 & 0 & 0 & \\
\hline Additional Fluoride measures & $1(2.0)$ & 0 & $2(4.0)$ & \\
\hline Fluoride toothpaste only & $26(52.0)$ & $31(62.0)$ & $34(68.0)$ & 0.262 \\
\hline No fluoride & $23(46.0)$ & $19(38.0)$ & $14(28.0)$ & \\
\hline \multicolumn{5}{|l|}{ Saliva Secretion Amount } \\
\hline Normal & $4(8.0)^{\mathrm{ab}}$ & $33(66.0)^{\mathrm{ac}}$ & $47(94.0)^{\mathrm{bc}}$ & \\
\hline Low (0.9-1.1 ml Stimulated) & $28(56.0)^{\mathrm{d}}$ & $17(34.0)^{\mathrm{e}}$ & $3(6.0)^{\mathrm{de}}$ & $0.001 *$ \\
\hline Low (0.5-0.9 ml Stimulated) & $18(36.0)^{\mathrm{fg}}$ & $0^{\mathrm{f}}$ & $0^{\mathrm{g}}$ & \\
\hline Very Low ( $\leq 0.5 \mathrm{ml}$ Saliva) & 0 & 0 & 0 & \\
\hline \multicolumn{5}{|l|}{ Saliva Buffer capacity } \\
\hline Adequate $(\mathrm{pH} \geq 6.0)$ & $4(8.0)^{\mathrm{ab}}$ & $28(56.0)^{\mathrm{ac}}$ & $44(88.0)^{\mathrm{bc}}$ & \\
\hline Reduced (pH 4.5-5.5) & $26(52.0)^{\mathrm{d}}$ & $22(44.0)^{\mathrm{e}}$ & $5(10.0)^{\mathrm{de}}$ & $0.001 *$ \\
\hline Low $(\mathrm{pH} \leq 4.0)$ & $20(40.0)^{\mathrm{fg}}$ & $0^{\mathrm{f}}$ & $1(2.0)^{\mathrm{g}}$ & \\
\hline Total & $50(100)$ & $50(100)$ & $50(100)$ & \\
\hline
\end{tabular}

Test applied: Chi-square test followed by Marascuilo procedure; ${ }^{*} \mathrm{p} \leq 0.05$ (statistically significant) Marascuilo procedure: Groups with same superscripted letter showed statistically significant difference.

The best predictors in the descending order for caries risk

were DMFT score followed by diet frequency with the variances $28.2 \%$ and $2.8 \%$ respectively (Table 3 ). 
Table 3: Stepwise Multiple Linear Regression analysis with caries risk as dependent variable

\begin{tabular}{|ccccc|}
\hline Model & \multicolumn{1}{c}{$\mathbf{R}$} & $\begin{array}{c}\mathbf{R}^{2} \\
\text { Caries Risk }\end{array}$ & F - value & p - value \\
1 & 0.531 (a) & 0.282 & 58.029 & 0.000 (a) \\
2 & 0.556 (b) & 0.028 & 5.853 & 0.000 (b) \\
& \multicolumn{2}{r}{ a. Predictors: (Constant), DMFT score } \\
& b. Predictors: (Constant), DMFT score, Diet frequency & \\
\end{tabular}

$\mathrm{R}^{2}=$ Coefficient of determination, $\mathrm{R}=$ Correlation coefficient, $\mathrm{p} \leq 0.05$ (statistically significant)

Smokers were found to be at maximum caries risk $[\mathrm{n}=28 \quad(56 \%)]$, followed by smokeless tobacco users $[\mathrm{n}=17$ $(34 \%)]$ and control $[\mathrm{n}=3(6 \%)]$ groups (Graph 1).

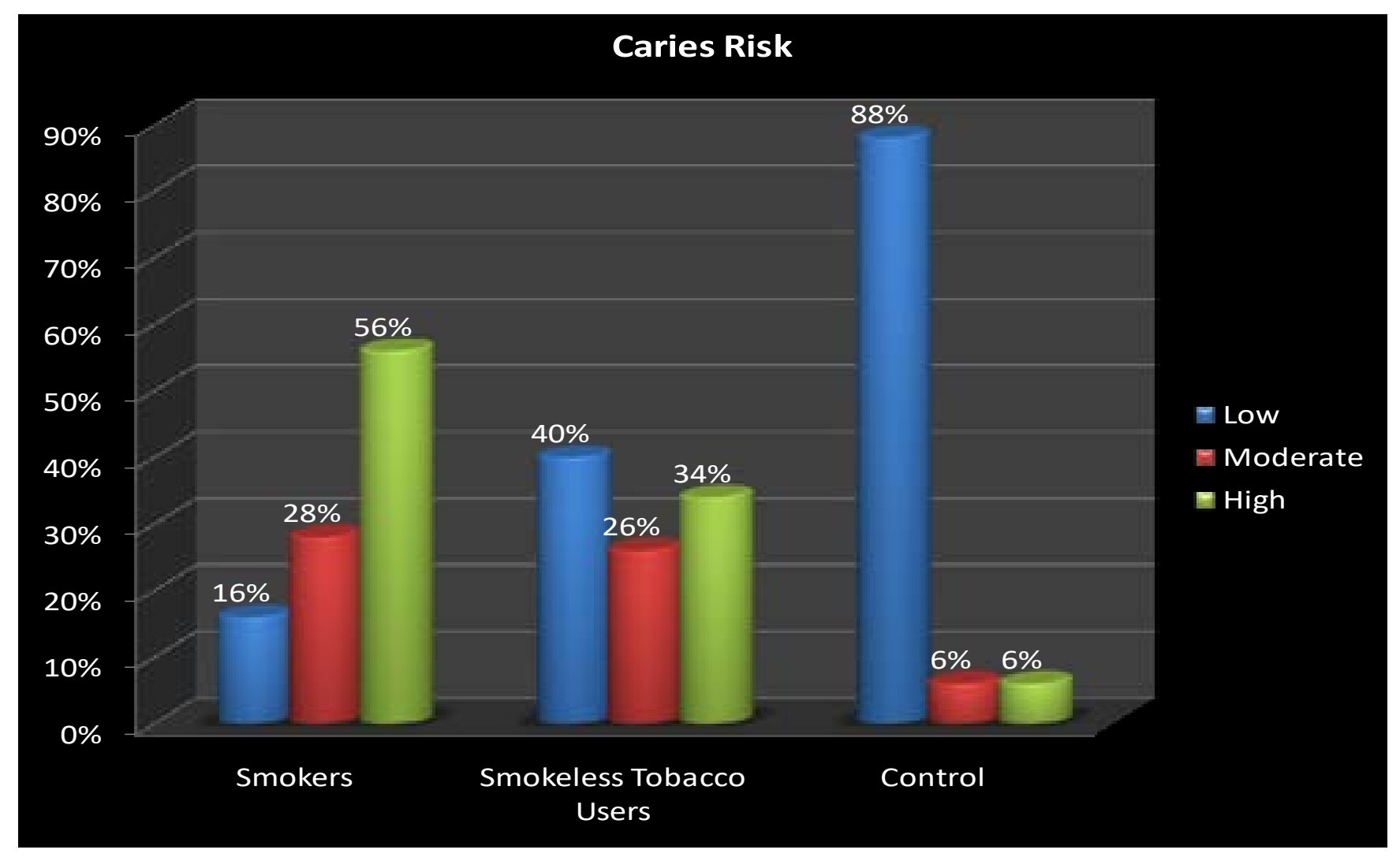

Graph 1: Comparative assessment of study population based on caries risk

Susceptibility sector was highest in the contribution of caries risk followed by bacteria, circumstances and diet sectors. Also smokers were found to have the least chance to avoid new caries $(41.3 \%)$ which depicted their caries risk to be the highest among the study groups (Graph 2, 3). 


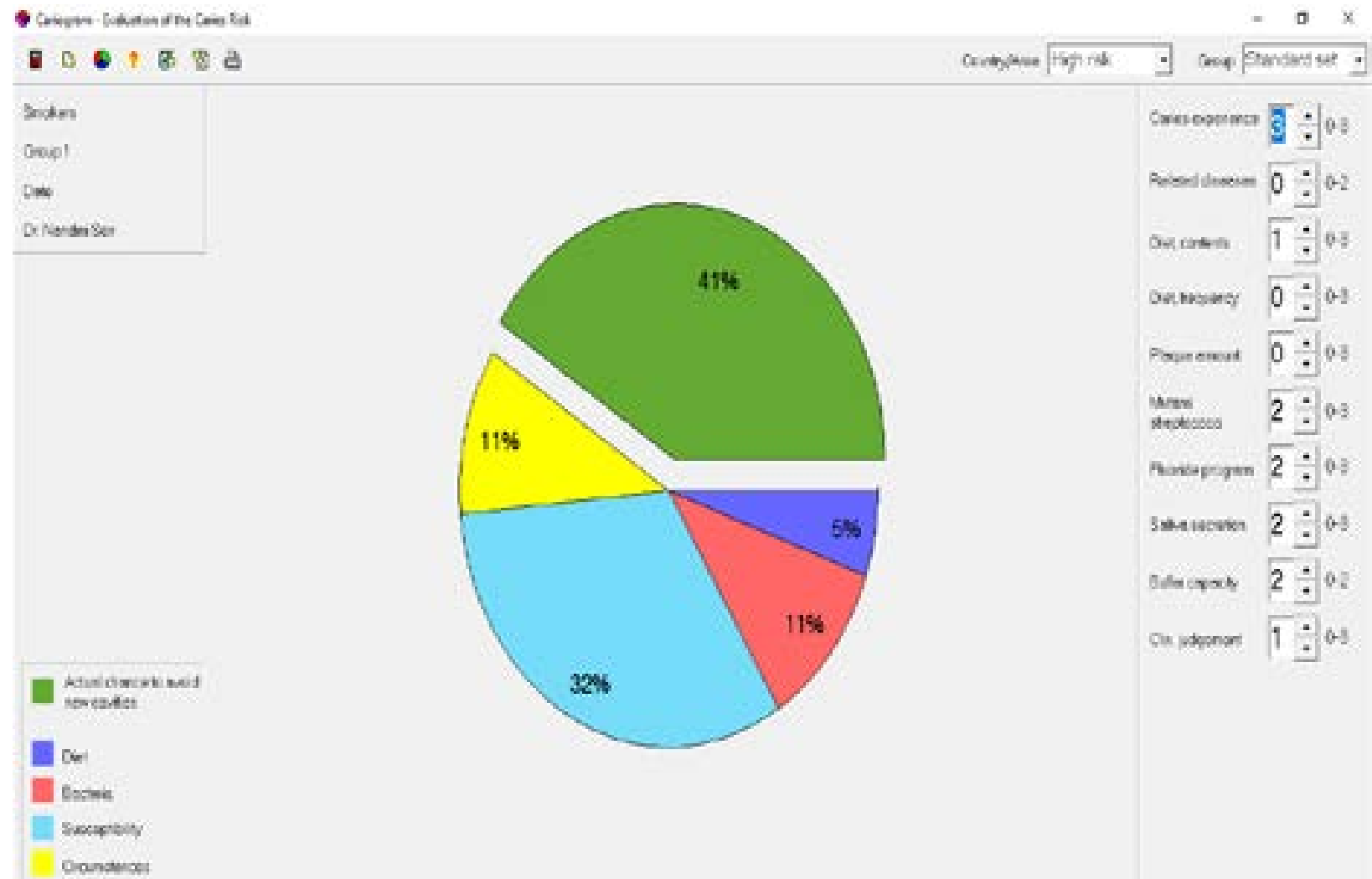

Graph 2: Mean percentage of individual sector in Cariogram contributing to caries risk among Smokers group

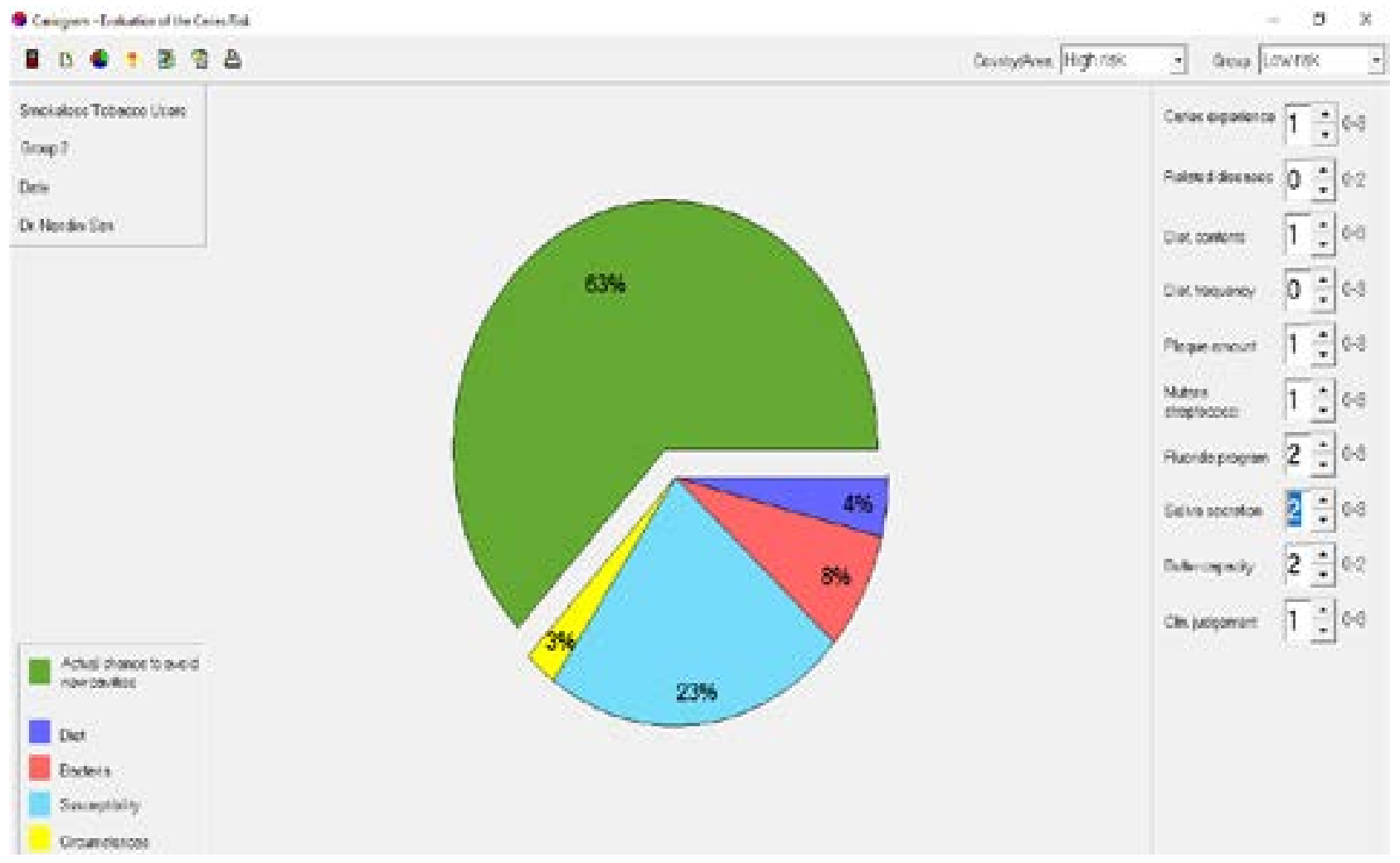

Graph 3: Mean percentage of individual sector in Cariogram contributing to caries risk among Smokeless Tobacco users group 


\section{Discussion}

Mankind has witnessed the detrimental effects of tobacco consumption on general and oral health from decades. Smokers group was found to have the highest caries experience, plaque, microbial count scores (High caries risk) as compared to smokeless tobacco users and controls. Susceptibility sector was highest $(31.3 \%)$ for smokers group which is indicative of infrequent fluoride exposure, reduced saliva flow and $\mathrm{pH}$ attributing to high caries risk. Majority of the smokers (56\%) were found to be at 'High caries risk', whereas $40 \%$ of the smokeless tobacco users were at 'Low caries risk'.

To the best of our knowledge, our study is the first one of its kind to have utilized the innovative cariogram model in the identification and comparison of caries risk among tobacco abusers i.e. smokers and smokeless tobacco users. Different studies have assessed caries risk \& prevalence in tobacco abusers but none had studied all the suspected causal factors for dental caries. The Cariogram model is capable of caries risk assessment in a better manner as it has most of the important risk factors incorporated in it and hence gives a comprehensive profile of caries risk of subjects.

However, the study exhibits certain limitations that needs to be addressed. Since the cariogram model was used, so a preset number of caries risk factors as mentioned in the cariogram manual were recorded. Other factors such as effect of tobacco (nicotine), proper diet history, oral hygiene practices were not considered. The study results are based on self-report, therefore tobacco consumption related responses may not be accurate.

In the current study, majority were males in the smokers and smokeless tobacco users groups, which is in agreement with the studies conducted by Rooban et al and Mohamed and Janakiram ${ }^{20,21}$. But conversely, a study by Lashkari and Shukla on smokeless tobacco users in Karnataka, India showed that females were about half of the study population $(45.9 \%)^{18}$. Among majority of Indian population due to cultural barriers, women have a natural tendency to hide, even if they were engaged in certain adverse habits like tobacco chewing or smoking bidi, which explains our demographic results with almost no females.
Our study results revealed that smokers $(72 \%)$ had higher DMFT scores than the smokeless tobacco users $(20 \%)$, which is in accordance with the findings by Rooban et $\mathrm{al}^{20}$. On the contrary, Hans et al on central jail prisoners portrayed that Smokeless tobacco users obtained higher DMFT scores than the smokers ${ }^{22}$.

Nagarajappa et al showed in their research that use of chewing tobacco decreased the Lactobacilli colony-forming units' count ${ }^{15}$. Similarly in the present study, the results showed that more than half of the Smokeless tobacco users $(72 \%)$ had very low lactobacilli count in comparison to smokers, while no statistically significant difference was detected between Lactobacilli count in smokers and smokeless tobacco users in the study by Mujahid et $\mathrm{al}^{16}$. A plausible reason might be that India is a developing country and most of the people belong to low or middle socio-economic strata which restricts their usage of refined confectionary sugar products.

Streptococcus mutans count was significantly associated with the smokers and smokeless tobacco consumers groups $(p=0.001)$ with majority of the smokers $(44 \%)$ showing 'High' count in the current study which is in accordance with the study by Roushdy ${ }^{23}$, where he had concluded that dental caries was correlated with Streptococci count and smoking but contrary findings were observed in the study by Mujahid et al where the mean Streptococcal count was maximum in the tobacco chewers with dental caries $\operatorname{group}^{16}$.

Majority $(60.7 \%)$ of the participants of the three study groups used fluoridated toothpaste only in routine while less than half of the study population $(37.3 \%)$ had no fluoride usage. Less usage of fluoride in our study population may have lead to higher caries risk which can be attributed to the lack of awareness and preventive programmes conducted at community level.

Tobacco usage in various forms have been found to affect the salivary parameters, consequently leading to oral diseases. Studies by Singh et al, Khan et al and Khoso et al reported that the smokers group had less saliva flow rate and $\mathrm{pH}$, as compared to smokeless tobacco users which is concurrent with the current study findings ${ }^{9,24,25}$. 
But dissimilar findings were portrayed in studies conducted by Grover et al, Chakrabarty et al, and Gopal et al ${ }^{26-28}$. In the present study, the low salivary flow rate and reduced $\mathrm{pH}$ amongst the smokers could be attested to the higher DMFT scores amongst them. Possible reason might be that the flushing action of saliva is impaired as the salivary flow rate decreases, which leads to accumulation of food debris and also acidic $\mathrm{pH}$ favours microbial growth which consequently may have contributed to higher caries prevalence among the smokers.

Overall findings of the present study are in accordance with numerous former studies where the authors have concluded that a positive correlation existed between

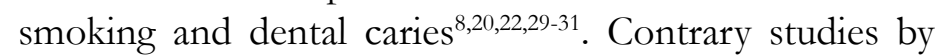
Lashkari and Shukla and Holmen et al confirmed that smokeless tobacco users were at higher caries risk than control group ${ }^{18,29}$. Stepwise multiple linear regression analysis depicted that DMFT score was the strongest predictor of caries risk.

The applicability of the Cariogram model still raises questions in our minds among the rural population, specially in developing countries like India. Hence we recommend to carry out similar studies separately among rural and urban population to see the impact of factors prevailing in these areas which can affect dental caries prevalence.

The findings from the different cariogram elements in this study converged to indicate that Smokers were at maximum caries risk, followed by smokeless tobacco users. The study also confirmed that Cariogram model could be a useful tool to represent caries risk among smokers and smokeless tobacco users. It is recommended that tobacco cessation and awareness programmes concerning the deleterious effects of tobacco should be conducted mandatorily to reduce its consumption. Dental outreach programmes and preventive public health care programmes need to be planned accordingly.

\section{Conflict of interest}

The Authors declare no conflict of interest.

\section{References}

1. Rani M, Bonu S, Jha P, Nguyen SN, Jamjoum L. Tobacco use in India: prevalence and predictors of smoking and chewing in a national cross sectional household survey. Tobacco Control 2003;12:e4.

2. Jha P, Jacob B, Gajalakshmi V, Gupta PC, Dhingra
N, Kumar R, et al. A nationally representative case-control study of smoking and death in India. N Engl J Med 2008;358:1137- 1147. PubMed.

3. Mishra S, Joseph RA, Gupta PC, Pezzack B, Ram F, Sinha DN, et al. Trends in bidi and cigarette smoking in India from 1998 to 2015, by age, gender and education. BMJ Global Health 2016;1:e000005.

4. Voelkar MA, Simmer-Beck M, Cole M, Keeven E, Tira D. Preliminary findings on the correlation of saliva $\mathrm{pH}$, buffering capacity, flow, consistency and streptococcus mutans in relation to cigarette smoking. The Journal of Dental Hygiene 2013 Feb;87(1):30-37.

5. Bruno-Ambrosius K., Swanholm G, Twetman S. Eating habits, smoking and toothbrushing in relation to dental caries: a 3-year study in Swedish female teenagers. Int J Paediatr Dent 2005 May;15(3):190-196.

6. Zitterbart PA, Matranga LF, Christen AG, Park KK, Potter RH. Association between cigarette smoking and the prevalence of dental caries in adult males. Gen Dent. 1990 Nov-Dec;38(6):426-431.

7. Weintraub JA, Burt BA. Periodontal effects and dental caries associated with smokeless tobacco use. Public Health Rep. 1987 Jan-Feb;102(1):30-35.

8. Shalini P, Niramathi K, Ranjith K, Preetha E Chaly, Indra Priyadarashini V, Nijesh Je. Dental caries experience among tobacco consuming truck drivers in North Chennai, India. International Journal Of Dental Research \& Development 2017 Feb;7(1):1-8.

9. Singh M, Ingle NA, Kaur N, Yadav P, Ingle E. Effect of long-term smoking on salivary flow rate and salivary pH. J Indian Assoc Public Health Dent 2015;13:11-13. 10. Goin RE, Hsu SC, Pollack RL, Haugh LD. Sugar and fluoride content of various forms of tobacco. J Am Dent Assoc. 1980 Jan;100(1):27-33.

11. Winn DM. Tobacco use and oral disease. J Dent Educ. 2001 Apr;65(4):306-312.

12. Bratthall D, Hansel Petersson G. Cariogram - a multifactorial risk assessment model for a multifactorial disease. Community Dent Oral Epidemiol 2005 Aug;33(4):256264.

13. Raju SH, Fareed N, Sudhir KM, Krishna Kumar R. Caries risk assessment among subjects with periodontal disease using cariogram study model. OHDM 2016 Aug;15(4):223-228.

14. Celik EU, Gokay N, Ates M. Efficiency of caries risk assessment in young adults using Cariogram. Eur J Dent 2012;6:270-279. PubMed.

15. Nagarajappa S, Prasad KVV. Oral Microbiota, Den- 
tal Caries and Periodontal Status in Smokeless Tobacco Chewers in Karnataka, India: A Case-control Study. Oral Health Prev Dent 2010;8(3):211-219.

16. Mujahid M, Anushree B, Shobha M. Salivary levels of cariogenic streptococcus and lactobacillus among tobacco abusers in Andhra Pradesh, India. Research Journal of Pharmaceutical, Biological and Chemical Sciences 2014;5(6):522-530.

17. Barman I, Umesh CPG. Effects of Habitual Arecanut and Tobacco Chewing on Resting Salivary Flow Rate and pH. Int J Oral Health Med Res 2015;2(1):13-18.

18. Lashkari KP, Shukla A. Prevalence of dental caries among smokeless tobacco chewers in Dakshina Kannada district population: A Cross Sectional Study. OHDM 2016 Dec;15(6):1-3.

19. Loe H. The Gingival Index, the Plaque Index and the Retention Index Systems. J Periodontol. 1967;38(Suppl 6):610-616.

20. Rooban T, Vidya KM, Joshua E, Rao A, Ranganathan S, Rao UK, et al. Tooth decay in alcohol and tobacco abusers. J Oral Maxillofac Pathol 2011;15:14-21.

21. Mohamed S, Janakiram C. Periodontal status among tobacco users in Karnataka, India. Indian J Public Health 2013;57:105-108.

22. Hans R, Thomas S, Dagli RJ, Solanki J, Arora G. Prevalence of dental caries among prisoners of Central Jail, Jodhpur City, Rajasthan, India. World Journal of Dentistry 2014 Apr-Jun;5(2):92-97.

23. Roushdy MM. Association of dental caries, streptococcus mutans counts and secretory $\operatorname{IgA}$ with tobacco smoking. Australian J Basic App Sci. 2009;3(4):32243229. PubMed.

24. Khan GJ, Javed M, Ishaq M. Effect of smoking on salivary flow rate. Gomal Journal of Medical Sciences 2010 Jul-Dec;8(2):221-224.

25. Khoso SA, Khan S, Aslam N, Memon S, Muneer G, Ahmed F, et al. Analysis of saliva flow rate and ph from addictive users of cohort of Hyderabad and adjoining area. World Journal of Pharmaceutical Research 2017;6(3):143-156.

26. Grover N, Sharma J, Sengupta S, Singh S, Singh N, Kaur H. Long-term effect of tobacco on unstimulated salivary pH. J Oral Maxillofac Pathol. 2016 Jan-Apr; 20(1):16-19.

27. Chakrabarty S, Patil S, Bandalore SR, Kempegowda RT, Shivu, Pewa S. A comparative study of long-term effect of tobacco on resting whole mouth salivary flow rate and pH. J Indian Acad Oral Med Radiol 2015;27:549-552. 28. Saraswathi Gopal K, Amala M, Harshavardhan BG. Effect of smoking and chewing tobacco on resting salivary flow rate and ph. International Journal of Current Research 2016;8(12):44344-44348.

29. Holmén A, Strömberg U, Magnusson K, Twetman S. Tobacco use and caries risk among adolescents - a longitudinal study in Sweden. BMC Oral Health 2013,13:31. 30. Al-Weheb AM. Smoking and its relation to caries experience and salivary lactobacilli count. J Coll Dentistry 2005;17(1):92-95.

31. Talpur N, Shah M, Siddique S. Tobacco use; impact and its co-relation with Dental Caries. Professional Med J 2017;24(7):1027-1030. PubMed. 